\title{
Illegitimate tasks and job satisfaction among employees of micro informal enterprises
}

\author{
Aamar Ilyas $^{a^{*}}$, Ramraini Ali Hassan ${ }^{a}$, Ahmed Hussain Khan ${ }^{b}$ and Waris Ali Khan ${ }^{a}$
}

${ }^{a}$ Universiti Malaysia Sabah, Malaysia

${ }^{b}$ National College of Business Administration \& Economics, Lahore, Pakistan

\section{H R O N I C L E}

\section{Article history:}

Received: June 26, 2020

Received in revised format:

June 302020

Accepted: July 26, 2020

Available online:

August 4, 2020

Keywords:

Illegitimate tasks

Job satisfaction

Stress-As-Offense-to-Self

Informal employee

Pakistan

\section{Introduction}

Research on the topic of individual employee welfare has been extensively recognized and welfare continues to be important to societal and organizational research (Griffin \& Clarke, 2011). Aamodt (2016) discussed two well-known measures of work welfare are intrinsic motivation and job satisfaction, but this study will only focus on job satisfaction. Structural determinants (e.g., Pay, workload, supervisory support, distributive justice, role conflict, role ambiguity, promotional chances, peer support, autonomy) have effects on job satisfaction (Kim, Price, Mueller and Watson, 1996). Job satisfaction has been connected to employee retention (Cowin, 2002), burnout (Kalliath and Morris, 2002), job performance (Wright and Cropanzano, 2000) and employee productivity (Bhatti \& Qureshi, 2007). In recent literature, working environment and stressful conditions have been frequently be seen to decline the level of job satisfaction (Raziq \& Maulabakhsh, 2015; Rubino et al., 2009). Stress at workplace increased the risk to well-being and also creates a threat to attainment of organizational daily, monthly and annual objectives (Lazarus, 1999). Leary (1999) stated that if employees work for self-image then goals are very important for them. This study addresses the illegitimate task-associated stressor that establishes a threat to the employees' self-image. More specifically, unreasonable and unnecessary tasks are in appropriate and interrupt the core norms and values associated with employee's occupational roles. Such lack of self-image and self-respect is likely to be supposed as unfair and highly stressful (Greenberg, 2010; Cropanzano et al., 2001). Tasks are considered as illegitimate and found to harm employees' health, emotions, and well-being (Kottwitz et al., 2013; Semmer et al., 2010). Illegitimate tasks are not linked with the core of employee's duty and or professional identity. Examples are; when an employee of a firm performs the responsibility of picking up and dropping our children from school, an accountant of firm also performs a duty as an owners driver.

* Corresponding author.

E-mail address: aamarilyas@gmail.com (A. Ilyas) 
The purpose of this study is to provide a clear picture on how illegitimate tasks impact on the employees' mind who work in micro informal enterprises. In the next section, the outline the concepts of job satisfaction and illegitimate tasks are discussed in details. After that methodology is described. The subsequent part of this study presents the results and discussion. Finally, concluding explanations are made in the lens of "Stress-As-Offense-to-Self" (SOS) theory and further research directions.

\section{Literature review}

Usually, the employees of multinational firms know what they do and do not on workplace. Therefore, MIE employees have no idea in morning at workplace what responsibilities would be assigned by supervisor or owner at workplace during that day (Kubicek et al., 2014). Such tasks are called illegitimate since employees are not expected to handle the given tasks. Illegitimate tasks were divided into two categories in literature: unreasonable and unnecessary (Semmer et al., 2015). Unnecessary task is when employee assigned a duty which he/she has already done. For example, employee completes the stock taking in afternoon and immediate boss repeats this activity form the same employees. Unreasonable task is when tasks are not matched with employee's profession or job description or occupation. For example, when immediate manager assigns the duties of marketing division to any employee who belongs to finance division. So far, these both tasks hold a humiliating message and reaction of these messages is that employees feel anger and indignation (Semmer et al., 2007, 2015). According to Stress-AsOffense-to-Self theory, such tasks are regarded as a form of social disrespect, disregard, and devaluation at workplace (Pierce \& Gardner, 2004; Semmer \& Beehr, 2014; Semmer et al., 2015). There are limited studies available in literature on the topic of illegitimate tasks, this theme consider is a relatively new topic in the field of management and organizational behavior. No single study examined this theme within informal enterprises.

\subsection{Job satisfaction}

Job satisfaction depends on both intrinsic and extrinsic aspects. Organizational, colleagues, educational support at workplace, and personal needs factors include in intrinsic aspect. Promotion and salary factors include in extrinsic aspects (Davis, 1996; Koeske et al., 1994). Spector (1997) presented a job satisfaction definition that consists of nine comprehensive aspects of employee's satisfaction (e.g., nature of work, contingent rewards, supervisor support, and promotion). According to Preston (1996), some negative workplace practices that leads to employee's dissatisfaction (e.g., negative perceptions towards peers, work inefficiency, lack of interest at work, and high absenteeism). One major reason for job dissatisfaction is firm's characteristics directly offer to employees (Carlan, 2007). Many practitioners and policy makers of this discipline have finished that organizational negative attribute adversely affects the happiness and comfort level of employees (Violanti \& Aron, 1994).

\subsection{Illegitimate tasks and job satisfaction}

Previous studies show that illegitimate tasks negatively effects on psychological separation, self-esteem, self-respect, Job satisfaction (Apostel, Syrek, \& Antoni., 2017; Eatough et al., 2016; Omansky et al., 2016; Semmer et al., 2015; Stocker et al., 2010). In this paper, the primary focus is on job satisfaction. Job satisfaction is related to different outcomes such as turnover intention, higher or lower performance and burnout level (Faragher et al., 2005; Griffeth et al., 2000; Judge et al., 2001). Employees perceive satisfaction or dissatisfaction at job because some tasks at workplace are meaningless and some meaningful (Hackman \& Oldham, 1975). We proposed that those employees who are upset and disturbed at job, engaged more illegitimate tasks.

\subsection{Theoretical framework}

The recently introduced SOS theory (Semmer et al., 2007, 2015) is based on the widely accepted notion since people generally try to maintain a positive self-image (Baumeister, 1996), negative experiences at work that threaten people's self-esteem cause stress reactions (Baumeister, 1996; Semmeret al., 2015). SOS theory conceptualizes and hypothesizes the behavioral, organizational, physiological and psychological responses to stress and diminishing performance in individual or organizational level. According to SOS theory we accept that illegitimate tasks threaten employees' satisfaction level. Previous empirically studies have indicated the negative relationship between illegitimate tasks and job satisfaction (Omansky et al., 2016; Eatogh et al., 2015, 2016; Stocker et al., 2010). Respondents and unit of analysis of these studies were formal enterprises. No single study examined this relationship among employees of informal enterprises. So, the conceptual framework of this research paper is developed as below:

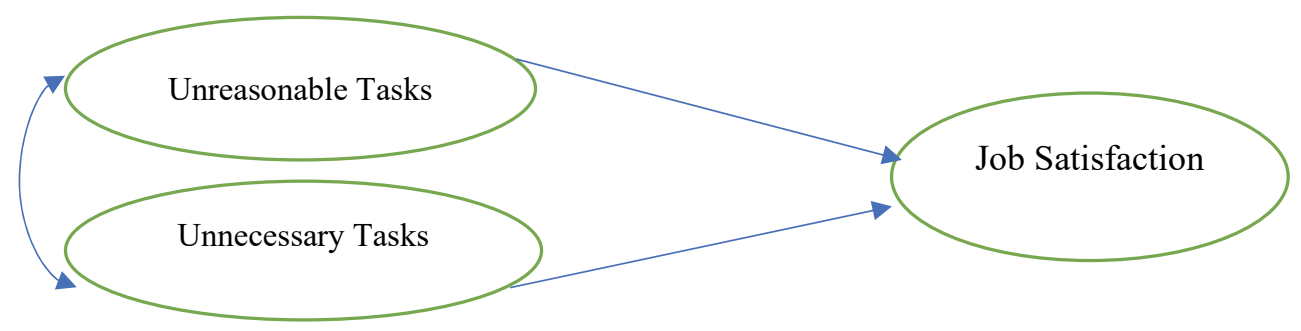

Fig. 1. Conceptual framework of illegitimate tasks and job satisfaction 


\section{Research hypotheses}

The following three hypotheses are proposed to assess the structural relations among given variables.

H1 MIE employees' unreasonable tasks are negatively associated with their job satisfaction.

H2 MIE employees' unnecessary tasks are negatively associated with their job satisfaction.

H3 MIE employees' unnecessary tasks are less influential than the MIE employees' unreasonable tasks on job dissatisfaction.

\section{Methodology}

\subsection{Survey instrument}

This study was used Bern Illegitimate Task Scale (BITS) with nine items to assess the illegitimate tasks developed by Semmer et al., (2010). We were not interested in a whole construct of illegitimate tasks. The Bern Illegitimate Task Scale (BITS) consists of two facets: (i) unnecessary tasks and (ii) unreasonable tasks. Sample item unnecessary tasks: "Do you have work tasks that make you question whether they have to be done at all?" and sample item unreasonable tasks: "Do you have work tasks that you believe are beyond your job scope and should not be expected from you?". Items of this scale consist on a 5point Likert scale ranging from 1 (strongly disagree) to 5 (strongly agree). The authors of this study compute reliability for both unnecessary tasks and unreasonable tasks, and found a .88 Cronbach's alpha score for the unnecessary tasks scale and found a .91 Cronbach's alpha score for the unreasonable tasks scale. Five indicators were for unnecessary tasks and four chosen for unreasonable tasks. Single and Multiple items scales were used to measure the job satisfaction in previously (e.g., Cammann et al., 1979; Spector, 1985; Nagy, 2002; Wanous et al., 1997). In order to measure the job satisfaction level of informal employees, five items Lytle (1994) scale was used in this study. Items of job satisfaction scale consist on a 5-point Likert scale ranging from 1 (strongly disagree) to 5 (strongly agree). The survey questions about job satisfaction are as follow: (i) "I consider my job pleasant", (ii) "I feel fairly-well satisfied with my present job", (iii) "I definitely like my work", (iv) "My job is pretty interesting", and (v) "I find real enjoyment in my work". Job satisfaction indicates very satisfactory Cronbach's alpha reliability coefficient $(\alpha=0.87)$.

\subsection{Sampling}

An active employee of micro informal enterprises (MIE's) within Lahore city is the unit of analysis of this study. The definition of informal enterprises used in this paper is those businesses that produce legal goods but do not register their businesses under the requirement of government authorities (Ilyas, Hassan, Khan, Abdurahman, Fahim, 2020). The target population for this survey is Lahore, provincial capital city of Pakistan. Lahore is divided into ten towns including one military cantonment, while survey is actually conducted in 20 markets of the five towns. These towns include Shalimar Town, Samanabad Town, Nishtar Town, Data Ganj Baksh Town, and Ravi Town. Snowball sampling technique used for picking the participants because no comprehensive list of informal employees exists in all 20 markets and Ilyas and Hassan (2019) also suggest snowball sampling technique if we collect information from informal enterprises since researchers do not know about their legal status. The questionnaire of the study was sent to 500 employees of informal enterprises. Participants were 425 full-time employees in informal enterprises at various position levels, representing an 85 percent response rate. Before to start the survey, employees were asked to give their consent. It was confirmed that the information and data of these employees would be treated confidential.

\subsection{Statistical methods}

SPSS 21 and AMOS 16 statistical packages were used to analyze the collected data. Normality of variables was checked with the help of Skewness and Kurtosis scores. Testing the hypotheses of this study was performed with the help of structural equation modeling (SEM). This analysis comprises confirmatory factor analysis (CFA) and structural equation modeling (SEM). Latent variable cannot be observed directly. So, confirmatory factor analysis was utilized to validate the latent variables model. In first stage, we checked the standardized regression weight to check the indicators' appropriateness. Significant indicators were included in measurement model and insignificant indicators were excluded from model. Hair et al., (1998) recommended a threshold $(0.50)$ for factor loading to simplify the model. So, all indicators were excluded from model which having lower loading than 0.50 . Overall model fit was produced with the help of AMOS statistical software to evaluate how well our measurement models fit the data. SEM is the final stage of statistical analysis; this phase assesses how data fit to driven theoretical model. According to Byrne (2001), SEM has quality to provide correctness in estimating the degree of relationship than other statistical analysis.

\section{Results}

\subsection{Descriptive analysis}

Of the 425 participants, approximately $11 \%$ having graduation and two-year college degree of the study participants ( $3 \%$ and $8 \%$ respectively). $31 \%$ participants having above $5^{\text {th }}$ grade school and remaining participants $(58 \%)$ of this study having 
primary education or had never gone to school. Age ranged of participants was from 14 to 69 years, with an average age of 29 years. 189 participants worked more than 18 years on the same job. 103 participants had between 10-18 years of services and the remaining participants (approximately $31.5 \%$ ) had less than 10 years of job experience on the same job.

\subsection{Measurement model of unnecessary tasks}

Confirmatory factor analysis (CFA) was carried out to validate the model of unnecessary tasks. The results of CFA show that the factor loadings of unnecessary tasks are significant ap $\mathrm{p} \leq .05$. Factor loadings of the following indicators, 'tobedoneatall' with value of 0.61 , 'makesenceatall' with value of 0.57 , 'organizeddiffertly' with value of 0.65 , 'otherlessmistake' with value of .68, are above the determined threshold (0.50) level. However, one indicator has below loading from determined threshold. This indicator was removed from the model of unnecessary tasks. The statistics of goodness-of-fit show that result did not acceptable for model fit. Literature shows that modification index is a good technique to improve the goodness-of-fit statistics of model fit (Schumacher and Lomax, 2004; Wan, 2002). A good model fit achieved after correlation the one pair of measurement errors (see Fig. 2).

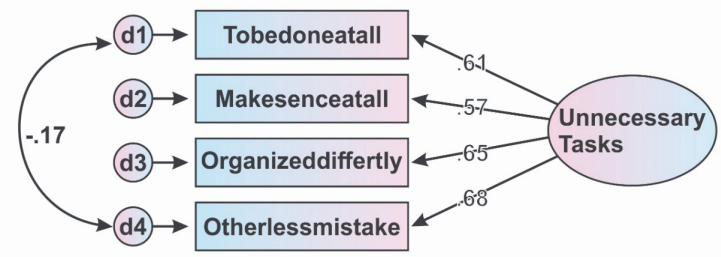

Fig. 2. Measurement model of unnecessary tasks

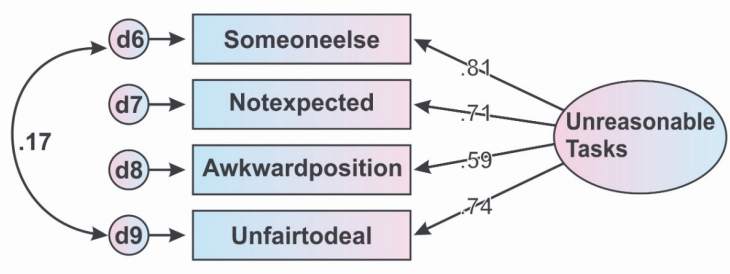

Fig. 3. Measurement model of unreasonable tasks

\subsection{Measurement model of unreasonable tasks}

An unreasonable task is the second exogenous latent variable. Four indicators of measurement model of unreasonable tasks, factor loadings were assessed by CFA to check the validity of these indicators. Confirmatory factor analysis (CFA) was carried out to validate the model of unreasonable tasks. The results of CFA show that the factor loadings of unreasonable tasks are significant at $\mathrm{p} \leq .05$. Factor loadings of the following indicators, 'someoneelse' with value of 0.80 , 'notexpected' with value of0.70, 'awkwardposition' with value of 0.59 , 'unfairtodeal' with value of .74, are above the determined threshold ( 0.50$)$ level (see Fig. 3).

\subsection{Measurement model of job satisfaction}

Job satisfaction was a latent variable in this study to measure the respondents' awareness about their job satisfaction, using five items developed on a 5-point Likert scale. The results of CFA show that the factor loadings of unnecessary tasks are significant ap $\mathrm{p} \leq .05$. Factor loadings of all indicators are above the determined threshold (0.50) level (see Fig. 4) except one indicator. Below threshold indicator was eliminated from the measurement model of job satisfaction. To reasonable results of model fit was achieved through four pairs of errors term were correlated with each other.

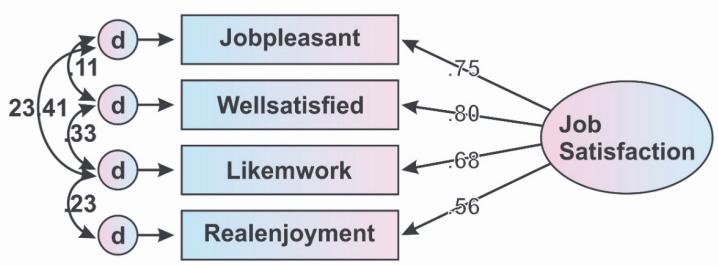

Fig. 4. Measurement model of job satisfaction

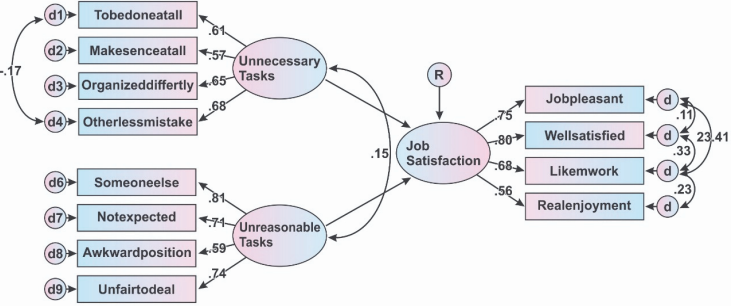

Fig. 5. Revised Structural Equation Model

\subsection{Structural equation model}

Wan (2002) and Gall et al. (2007) stated in their studies that structural equation model is a decent statistical practice to explore relationship among variables. However, SEM procedure was used in this study to explore the causal links among unnecessary tasks, unreasonable tasks, and job satisfaction variables. Scores of the Skewness and kurtosis of these variables reveals that variables of this study are normally distributed. For the dependent variable of job satisfaction, findings from SEM demonstrate that unnecessary and unreasonable tasks are significantly and negatively related to job satisfaction with regression weights of -.28 and -.16 (see Fig. 5) respectively. These findings show that as unnecessary tasks, unreasonable tasks increase, job satisfaction decrease. A positive correlation was noticed (correlation coefficient .15 at $\mathrm{p} \leq .05$ ) among unnecessary tasks and unreasonable tasks. In general, independent variables unnecessary tasks and unreasonable tasks account for $21 \%$ of the variance in the job satisfaction. 
Table 1

Goodness-of-fit statistics for Structural Equation Model

\begin{tabular}{|c|c|c|}
\hline Index (Symbols) & Criteria & Model \\
\hline Chi-square $\left(x^{2}\right)$ & Smaller the better & 1025.636 \\
\hline Chi-square associated p-value (P) & $\geq .05$ & 0.02 \\
\hline Root mean square error of approximation (RMSEA) & $.05<$ value $\leq .08:$ acceptable $\leq .05:$ good & 0.046 \\
\hline Chi-square / Degree of freedom $\left(x^{2} / d f\right)$ & $\leq 2 ; \geq 3 ; \leq 4$ & 1.871 \\
\hline Tucker-Lewis index (TLI) & $.90 \leq$ value $<.95:$ acceptable $\geq .95:$ good & 0.922 \\
\hline RMSEA associated $\mathrm{p}$ value (PCLOSE) & $\geq .05$ & 0.812 \\
\hline Comparative fit index (CFI) & $.90 \leq$ value $<.95:$ acceptable $\geq .95:$ good & 0.953 \\
\hline Hoelter's critical N & $75 \leq$ value $<200:$ acceptable $\geq 200:$ good & 283 \\
\hline Standardized root mean square residual (SRMR) & $.05 \leq$ value < .08: acceptable $\geq .05:$ good & 0.0625 \\
\hline
\end{tabular}

The following three hypotheses were formulated with the help of theoretical framework and results of literature review;

$\mathrm{H}_{1}$ MIE employees' unnecessary tasks are negatively associated with their job satisfaction.

The first hypothesis is supported because findings show that unnecessary task has a negative and significant $(\beta=-0.279, \mathrm{P}<$ 0.05 ) effect on the level of job satisfaction. Results of unstandardized regression (coefficient - .494) show that one SD (standard deviation) increase in unnecessary tasks would decrease .49 in the level of job satisfaction.

$\mathrm{H}_{2}$ MIE employees' unreasonable tasks are negatively associated with their job satisfaction.

This second hypothesis of this study is also supported with findings of literature review. The results show that unreasonable task has a significant and negative effect on the level of job satisfaction $(\beta=-0.163, P<0.05)$. Results of unstandardized regression (coefficient - .352) show that one SD (standard deviation) increase in unreasonable tasks would decrease .352 in the level of job satisfaction.

$\mathrm{H}_{3}$ MIE employees' unnecessary tasks are less influential than the MIE employees' unreasonable tasks on job satisfaction.

The results show that the unreasonable task has comparatively lower regression coefficient (-0.163) weight. Unnecessary tasks have relatively higher negative effect on the level of job satisfaction with coefficient value -0.279 . The findings confirm that MIE employees' unreasonable tasks are less influential than the MIE employees' unnecessary tasks on job satisfaction. The final hypothesis of this study is also supported.

\section{Conclusions}

The basic question of this research was to study the nature of the relationship among illegitimate tasks and job satisfaction. The results of this paper have supported the hypotheses that the more MIE employee' perceive unreasonable tasks at organization, the lower they are satisfied with their jobs. Similar results come for unnecessary tasks. If employees of MIE perceive high stress; they are less likely to report of job satisfaction. The findings of this thesis also reveal that unreasonable tasks are more negatively influential than unnecessary tasks of MIE employees. Findings required a modification of managerial style and restructuring tough existing policy to assign tasks to employees of MIE. Empirical evidences have shown the illegitimate tasks are major factors for stress-full environment within workplaces of formal and informal enterprises. The findings of this study have shown that illegitimate tasks also boost the stress level of employees who work in informal entrepreneurship. Therefore manager, owners, and supervisors of MIE must pay more notice on rationalization of every task to increase the level of job satisfaction at the place of work. Therefore, managers, owner, and supervisor of MIE should provide reasons, explanations, and judgments to their junior and encourage their junior to draw the significance and necessity of tasks why appoint us on this task. These explanations may be changeable according to time, employees, and place. Findings have shown that low illegitimate tasks should improve the clarity of job description. Consequently, owners and managers of MIE should organize and design such training programs that increase the level of understanding about assigned tasks.

\section{References}

Aamodt, R. (2016). Industrial/Organizational Psychology: An Applied Approach, $8^{\text {th }}$ ed., Belmont, CA: Wadsworth.

Apostel, E., Syrek, C.J., \& Antoni, C. H. (2017). Turnover intention as a response to illegitimate tasks: The moderating role of appreciative leadership. International Journal of Stress Management, 25, 234-249.

Baumeister, R. F., \& Leary, M. R. (1995). The need to belong: Desire for interpersonal attachments as a fundamental human motivation. Psychological Bulletin, 117, 497-529.

Bhatti, K. K., \& Qureshi, T. M. (2007). Impact of employee participation on job satisfaction, employee commitment and employee productivity. International Review of Business Research Papers, 3(2), 54-68.

Byrne, B. M. (2001). Structural equation modeling with AMOS, EQS, and LISREL: Comparative approaches to testing for the factorial validity of a measuring instrument. International Journal of Testing, 1(1), 55-86.

Carlan, P. E. (2007). The search for job satisfaction: A survey of Alabama policing. American Journal of Criminal Justice, 32(1-2), 74-86.

Cowin, L. (2002). The effects of nurses' job satisfaction on retention: an Australian perspective. JONA: The Journal of Nursing Administration, 32(5), 283-291. 
Cropanzano, R., Byrne, Z. S., Bobocel, D., \& Rupp, D. E. (2001). Moral virtues, fairness heuristics, social entities, and other denizens of organizational justice. Journal of Vocational Behavior, 58, 164-209.

Davis, A. J. (1996). A re-analysis of the occupational stress indicator. Work and Stress, 10(2), $174-182$.

Eatough, E. M., Meier, L. L., Igic, I., Elfering, A., Spector, P. E., \& Semmer, N. K. (2016). You want me to do what? Two daily diary studies of illegitimate tasks and employee well-being. Journal of Organizational Behavior, 37, $108-127$.

Faragher, E. B., Cass, M., \& Cooper, C. L. (2013). The relationship between job satisfaction and health: a meta-analysis. In From Stress to Wellbeing, 1 (pp. 254-271). Palgrave Macmillan, London.

Gall, M. D., Gall, J. P., \& Borg, W. R. (2007). Educational research: An introduction. Boston:

Griffin, M. A., \& Clarke, S. (2011). "Stress and well-being at work," in APA Handbook of Industrial and Organizational Psychology, Vol. 3, ed. S. Zedack (Washington, DC: American Psychological Association), 359-397.

Griffin, M. A., \& Clarke, S. (2011). "Stress and well-being at work," in APA Handbook of Industrial and Organizational Psychology, Vol. 3, ed. S. Zedack (Washington, DC: American Psychological Association), 359-397.

Hackman, J., \& Oldham, G. R. (1975). Work Redesign. Reading; MA: Addison-Wesley.?

Hair, J. F., Black, W. C., Babin, B. J., Anderson, R. E., \& Tatham, R. L. (1998). Multivariate data analysis (Vol. 5, No. 3, pp. 207-219). Upper Saddle River, NJ: Prentice hall.

Ilyas, A., \& Hassan, R. B. A. (2019). Suitable research methods for informal entrepreneurship. International Journal of Current Research, 11(2), 1025-1029.

Ilyas, A., Hassan, R. A., Khan, W. A., bin Abang Abdurahman, A. Z., \& Fahim, S. M. (2020). Important Determinants of Informal Entrepreneurs. Journal of Talent Development and Excellence, 12(3s), 2697-2714.

Judge, T. A., Erez, A., Bono, J. E., \& Thoresen, C. J. (2002). Are measures of self-esteem, neuroticism, locus of control, and generalized self-efficacy indicators of a common core construct?. Journal of Personality and Social Psychology, 83(3), 693.

Kalliath, T., \& Morris, R. (2002). Job satisfaction among nurses: a predictor of burnout levels. JONA: The Journal of Nursing Administration, 32(12), 648-654.

Koeske, G. F., Kirk, S. A., Koeske, R. D., \& Rauktis, M. B. (1994). Measuring the Monday blues: Validation of a job satisfaction scale for the human services. Social Work Research, 18(1), 27-35.

Kottwitz, M. U., Meier, L. L., Jacobshagen, N., Kälin, W., Elfering, A., Hennig, J., \& Semmer, N. K. (2013). Illegitimate tasks associated with higher cortisol levels among male employees when subjective health is relatively low: an intra-individual analysis. Scandinavian Journal of Work, Environment \& Health, 39(3), 310-318.

Kubicek, B., Korunka, C., Paškvan, M., Prem, R., \& Gerdenitsch, C. (2014). Changing working conditions at the onset of the twenty-first century: Facts from international datasets. In C. Korunka \& P. Hoonakker (Eds.), The Impact of ICT on quality of working life (pp. 2541). Dordrecht: Springer Netherlands.

Leary, M. R., \& Baumeister, R. F. (2000). The nature and function of self-esteem: Sociometer theory. Advances in Experimental Social Psychology, 32, 1-62.

Nagy, M. S. (2002). Using a single-item approach to measure facet job satisfaction. Journal of Occupational and Organizational Psychology, 75, 77-86.

Omansky, R., Eatough, E. M., \& Fila, M. J. (2016). Illegitimate tasks as an impediment to job satisfaction and intrinsic motivation: Moderated mediation effects of gender and effort-reward imbalance. Frontiers in Psychology, 7, 1818.

Pierce, J. L., \& Gardner, D. G. (2004). Self-esteem within the work and organizational context: A review of the organization-based selfesteem literature. Journal of Management, 30, 591-622.

Preston, P. (1996). Stress management. Administrative Radiology Journal. 15(8), 24-27.

Raziq, A., \& Maulabakhsh, R. (2015). Impact of working environment on job satisfaction. Procedia Economics and Finance, $23,717-725$.

Rubino, C., Luksyte, A., Perry, S. J., \& Volpone, S. D. (2009). How do stressors lead to burnout? The mediating role of motivation. Journal of Occupational Health Psychology, 14(3), 289.

Semmer, N. K., Jacobshagen, N., Meier, L. L., Elfering, A., Beehr, T. A., Kalin, W., et al. (2015). Illegitimate tasks as a source of work stress. Work Stress, 29, 32-56.

Semmer, N. K., Tschan, F., Meier, L. L., Facchin, S., and Jacobshagen, N. (2010). Illegitimate tasks and counterproductive work behavior. Applied Psychology, 59, 70-96.

Semmer, N., Jacobshagen, N., Meier, L., \& Elfering, A. (2007). Occupational stress research: the "stress as offense to self" perspective. in Occupational Health Psychology: European Perspectives on Research, Education and Practice, eds J. Houdmont and S. McIntyre (Portugal: ISMAI Publishing), 43-60.

Sonnentag, S., \& Lischetzke, T. (2017). Illegitimate tasks reach into afterwork hours: A multilevel study. Journal of Occupational Health Psychology, 23,248-261.

Spector, P. E. (1997). Job satisfaction: Application, assessment, cause, and consequences. Sage Publications, Inc

Stocker, D., Jacobshagen, N., Semmer, N. K., \& Annen, H. (2010). Appreciation at work in the Swiss armed forces. Swiss Journal of Psychology, 69, 117-124.

Violanti, J. M., \& Aron, F. (1994). Ranking police stressors. Psychological Reports, 75(2), 824-826.

Wan, T. T. H. (2002). Evidence-based health care management: Multivariate modeling approaches (1st ed.). Norwell, MA: Kluwer Academic Publishers.

Wanous, J. P., Reichers, A. E., \& Hudy, M. J. (1997). Overall job satisfaction: How good are single-item measures? Journal of Applied Psychology, 82, 247-252.

Wright, T. A., \& Cropanzano, R. (2000). Psychological well-being and job satisfaction as predictors of job performance. Journal of Occupational Health Psychology, 5(1), 84.

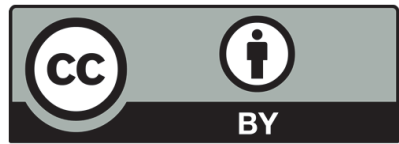

(C) 2020 by the authors; licensee Growing Science, Canada. This is an open access article distributed under the terms and conditions of the Creative Commons Attribution (CC-BY) license (http://creativecommons.org/licenses/by/4.0/). 